\title{
Risk factors for hemodynamic instability during laparoscopic pheochromocytoma resection: a retrospective cohort study
}

\author{
Magdalena Pisarska-Adamczyk ${ }^{1,2} \wedge$, Karolina Zawadzka ${ }^{1}$, Krzysztof Więckowski ${ }^{1}$, Krzysztof Przęczek ${ }^{1}$, \\ Piotr Major $^{1,2}$, Michał Wysocki ${ }^{1,2}$, Piotr Małczak ${ }^{1,2}$, Michał Pędziwiatr ${ }^{1,2}$ \\ ${ }^{1}$ 2nd Department of General Surgery, Jagiellonian University Medical College, Kraków, Poland; ${ }^{2}$ Centre for Research, Training and Innovation in \\ Surgery (CERTAIN Surgery), Kraków, Poland \\ Contributions: (I) Conception and design: M Pisarska-Adamczyk, M Pędziwiatr; (II) Administrative support: P Major, M Pędziwiatr; (III) Provision of \\ study materials or patients: M Pisarska-Adamczyk, P Major, M Wysocki, P Małczak; (IV) Collection and assembly of data: M Pisarska-Adamczyk, K \\ Zawadzka, K Więckowski, K Przęczek, P Major, M Wysocki, P Małczak; (V) Data analysis and interpretation: M Pisarska-Adamczyk, K Zawadzka, K \\ Więckowski; (VI) Manuscript writing: All authors; (VII) Final approval of manuscript: All authors. \\ Correspondence to: Magdalena Pisarska-Adamczyk, MD, PhD. $2^{\text {nd }}$ Department of General Surgery, Jagiellonian University Medical College, \\ Jakubowskiego 2, 30-688 Kraków, Poland. Email: magdalenapisarska@interia.pl.
}

Backgroundk Adrenalectomy for pheochromocytoma, a rare catecholamine-secreting tumour, is a challenging procedure because of the high risk of intraoperative hemodynamic instability, which can cause life-threatening complications. Our study aimed to identify predictive factors for hemodynamic instability during pheochromocytoma resection as well as to assess the risk factors for postoperative morbidity.

Methods: Data of 96 patients, who underwent laparoscopic adrenalectomy were analysed retrospectively. Hemodynamic instability was defined as an occurrence of both intraoperative episodes of systolic blood pressure above $160 \mathrm{mmHg}$ and vasoactive (vasodilators or vasoconstrictors) drug administration. Patients were divided into two groups: one which met both criteria, and another one without hemodynamic instability-42 (43.8\%) and $54(56.2 \%)$ respectively.

Results: The mean tumour size was $4.5 \pm 2.0 \mathrm{~cm}$. 86 patients had a sporadic pheochromocytoma and 10 (10.4\%) had a familial disease. 63 patients were preoperatively treated with nonselective blockers and 33 patients with selective blockers. Mean operative time was $98.7 \pm 41.7 \mathrm{~min}$. and mean intraoperative blood loss was $165.7 \pm 381.2 \mathrm{~mL}$. In $26 \%$ of patients, postoperative complications occurred. The median length of hospital stay was 3 days. The multivariate logistic regression model showed that the size of adrenal tumour and diabetes were significant factors of hemodynamic instability. Intraoperative use of vasopressors was an independent risk factor for both all-cause and cardiovascular morbidity.

Conclusions: Adrenal tumour size and diabetes were associated with hemodynamic instability during pheochromocytoma resection. The only risk factor for complications in our group was intraoperative necessity to use vasopressors.

Keywords: Adrenal glands; catecholamine's; hemodynamic instability; laparoscopy; pheochromocytoma

Submitted Nov 13, 2020. Accepted for publication Jan 14, 2021.

doi: $10.21037 /$ gs-20-783

View this article at: http://dx.doi.org/10.21037/gs-20-783

\footnotetext{
^ ORCID: 0000-0001-8936-1977.
} 


\section{Introduction}

Pheochromocytoma is a rare catecholamine-secreting tumour arising from chromaffin cells of the adrenal gland. The most common symptoms of pheochromocytoma are headaches, palpitations, and hyperhidrosis (1). Uncontrolled release of catecholamines can lead to arrhythmias, stroke, or a life-threatening hypertensive crisis. Despite improvements in surgical techniques and anaesthetic management, surgical resection, the only curative treatment, is still considered a challenging procedure. The main problem is the high risk of perioperative incidence of hemodynamic instability (HI).

Perioperative $\mathrm{HI}$ is unpredictable and is presumed to be responsible for the majority of morbidity in this group of patients. Moreover, the predictive risk factors remain unclear (2-4). Previous studies have described some risk factors of perioperative $\mathrm{HI}$, but the results were inconclusive, mostly due to different definitions of $\mathrm{HI}(5-8)$.

Our study aimed to define perioperative HI during laparoscopic adrenalectomy for pheochromocytoma, estimate the incidence of perioperative HI, identify predictive factors of perioperative $\mathrm{HI}$ and assess the risk factors for postoperative morbidity.

We present the following article in accordance with the STROBE reporting checklist (9) (available at http://dx.doi. org/10.21037/gs-20-783).

\section{Methods}

\section{Patients}

The study was a retrospective observation of consecutive patients with histologically confirmed pheochromocytoma undergoing laparoscopic adrenalectomy between the years 2003 and 2019. During the study period, 775 patients with adrenal pathology were treated. We excluded 6 patients initially submitted to open surgery and 2 patients who required conversion. 156 patients preoperatively were prepared as pheochromocytoma based on preoperative tests of methoxycatecholamines and imaging tests and 97 of them were later confirmed in histopathological exam. One of the patients was excluded due to a bilateral tumour. Only patients undergoing radical surgery were qualified for the study when the disease was limited to the adrenal glands.

Additionally, 9 patients were not suspected to have pheochromocytoma before surgery (the results of methoxycatecholamines in the daily urine collection and routine laboratory tests were within the normal range.), but they were confirmed postoperatively-they were not included in analysis.

The study endpoint was the incidence of perioperative HI. Figure 1 shows the patient flow through the study.

\section{Definition}

Brunaud and Bruynzeel indicated that systolic blood pressure (SBP) above $160 \mathrm{mmHg}$ was a risk factor for $\mathrm{HI}$ during pheochromocytoma surgery $(3,10)$ and studies by Aksakal et al. have revealed that HI was associated with the requirement of cardioactive or vasoactive drugs administration (11-13). Integrating these conclusions, we defined $\mathrm{HI}$ as an occurrence of both of the following criteria: intraoperative episodes of SBP above $160 \mathrm{mmHg}$ and requirement of vasoactive drug administration.

\section{Diagnosis and preparation for surgery}

The preoperative diagnosis of pheochromocytoma was made in the endocrinology department. Preoperative staging in all cases consisted of computed tomography (CT) or/and magnetic resonance imaging. Prior to surgery, a routine panel of laboratory tests was carried out to establish the hormonal activity of the tumour. The evaluation included plasma cortisol, adrenocorticotropic hormone, dehydroepiandrosterone sulfate, 17-OH-progesterone, testosterone, aldosterone, urinary free cortisol, and aldosterone, plasma renin activity, and dexamethasone suppression test. The catecholamines' metabolites (metanephrine, normetanephrine, and methoxytyramine) were measured from 24-hour urine collection.

Perioperative protocol covered all pre-, intra-, and postoperative issues that may reduce the risk of hemodynamic instability (14). All patients were preoperatively treated with phenoxybenzamine (irreversible, non-competitive alpha-blocker) or alternative doxazosin (selective alpha-blocker). Therapy was introduced 2 weeks before the surgery. The dose of phenoxybenzamine and doxazosin were gradually increased every 48 hours from $10 \mathrm{mg}$ twice a day and $2 \mathrm{mg}$ twice a day, respectively. Additionally, beta-blockers in case of coexisting tachycardia were given.

\section{Surgery}

Procedures were performed by experienced laparoscopic surgeons with extensive expertise in adrenal surgery $(>50$ cases per surgeon). 


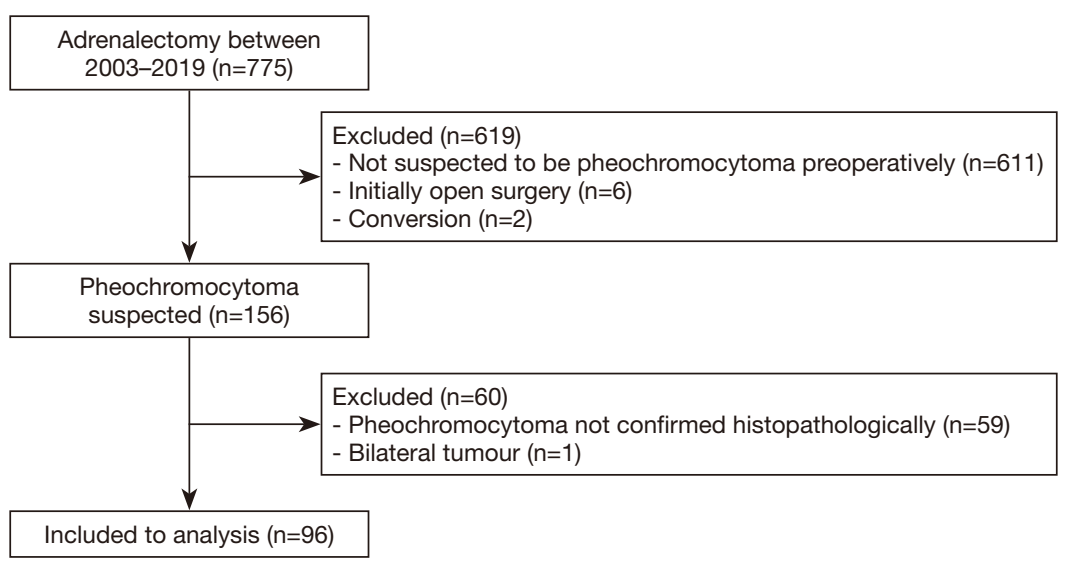

Figure 1 Patient flow chart.

In the morning of the operation, preinduction blood pressure was measured. Pneumoperitoneum was achieved by insufflating $\mathrm{CO}_{2}$ gas to an intraperitoneal pressure of $12 \mathrm{mmHg}$.

The operative method of choice in our department is laparoscopic transperitoneal lateral total adrenalectomy, which is performed similarly to described elsewhere $(15-17)$. The main adrenal vein was dissected and clipped before gland mobilization.

The anaesthetic protocol typical for this type of tumour was previously described (18). Intraoperatively SBP and diastolic blood pressure (DBP) were measured, monitored, and recorded every 10 minutes. To treat hypertensive and hypotensive episodes, intravenous doses of urapidil, ephedrine, nitrates, $\mathrm{MgSO}_{4}$, norepinephrine, or ß-blockers were administered.

\section{Data collection}

Electronic and paper-based patient records were reviewed and demographic data, tumour characteristics, and treatment details were collected. Patients' demographics (gender, age, body mass index (BMI)), American Society of Anaesthesiologists physical status classification system (ASA), comorbidities (diabetes mellitus, arterial hypertension, coronary heart disease, chronic obstructive pulmonary disease, renal, liver, and cerebrovascular diseases), history of previous abdominal surgeries and presence of hereditary cancer-related syndromes associated with the development of pheochromocytoma [multiple endocrine neoplasia type 2A (MEN 2A), MEN 2B, von Hippel-Lindau syndrome (VHL), neurofibromatosis type 1
(NF1)] were recorded.

Additionally, characteristics of the disease such as location, size on preoperative imaging, clinical stage, Pheochromocytoma of the Adrenal Gland Scaled Score (PASS), and catecholamines' metabolites secretion (urinary 24-hour excretion of metanephrine, normetanephrine, and 3 -methoxytyramine) were reported. Treatment detailspharmacological preparation, duration of anaesthesia and surgery, perioperative fluid management (type and number of administered fluids), estimated blood loss, need for blood transfusion, use of beta-blockers, vasodilators, and vasopressors were collected as well.

Vasopressor and fluid requirement after surgery, length of stay, complications, all-cause readmission, and death within 30 days were recorded. Data on morbidity were classified according to the Clavien-Dindo classification. Cardiovascular morbidity was defined as postoperative morbidity related to the cardiovascular system: postoperative hypotensive or hypertensive episodes requiring pharmacologic treatment, need for blood transfusion, myocardial or digestive ischemia, stroke, and postoperative hospitalization in intensive care unit (ICU) for cardiac-related causes.

\section{Statistical analysis}

The results were presented as mean \pm standard deviation (SD), or median and interquartile range (IQR) when appropriate. Student's $t$-tests were used to compare the means of two continuous normally distributed variables, while the Mann-Whitney U-tests were used to compare the medians of two continuous skewed variables. Chi-Squared 
Table 1 Demographic analysis of patient group and tumour characteristics

\begin{tabular}{|c|c|}
\hline Parameter & Value \\
\hline Number of patients, $n$ & 96 \\
\hline \multicolumn{2}{|l|}{ Sex, n (\%) } \\
\hline Females & $52(54.2)$ \\
\hline Males & $44(45.8)$ \\
\hline Mean age (years), mean \pm SD & $52.6 \pm 16.3$ \\
\hline Mean BMI $\left(\mathrm{kg} / \mathrm{m}^{2}\right)$, mean $\pm \mathrm{SD}$ & $26.4 \pm 5.4$ \\
\hline \multicolumn{2}{|l|}{ ASA scale, $\mathrm{n}(\%)$} \\
\hline ASA 1 & $2(2.1)$ \\
\hline ASA 2 & $49(51.0)$ \\
\hline ASA 3 & $42(43.8)$ \\
\hline ASA 4 & $3(3.1)$ \\
\hline Comorbidities, n (\%) & $75(78.1)$ \\
\hline Cardiovascular disease & $25(26.0)$ \\
\hline Arterial hypertension & $56(58.3)$ \\
\hline Diabetes, n (n\%) & $36(37.5)$ \\
\hline Pulmonary disease & $7(7.3)$ \\
\hline Renal disease & $6(6.3)$ \\
\hline Liver disease & $4(4.2)$ \\
\hline Cerebrovascular disease & $5(5.2)$ \\
\hline Genetic syndrome, n (\%) & $10(10.4)$ \\
\hline MEN 2A & $3(3.1)$ \\
\hline MEN 2B & $2(2.1)$ \\
\hline VHL & $1(1.0)$ \\
\hline NF1 & $4(4.2)$ \\
\hline Previous abdominal surgery, n (\%) & $36(37.5)$ \\
\hline \multicolumn{2}{|l|}{ Tumour location, n (\%) } \\
\hline Right adrenal gland & $55(57.3)$ \\
\hline Left adrenal gland & $41(42.7)$ \\
\hline Mean size of the tumour $(\mathrm{cm})$ mean $\pm \mathrm{SD}$ & $4.5 \pm 2.0$ \\
\hline $\begin{array}{l}\text { Mean urine metanephrine }(\mu \mathrm{L} / 24 \mathrm{~h}) \\
\text { mean } \pm \mathrm{SD}\end{array}$ & $3075.6 \pm 4915.3$ \\
\hline $\begin{array}{l}\text { Mean urine normetanephrine }(\mu \mathrm{L} / 24 \mathrm{~h}) \text {, } \\
\text { mean } \pm \mathrm{SD}\end{array}$ & $4668.7 \pm 6450.1$ \\
\hline $\begin{array}{l}\text { Mean urine methoxytyramine }(\mu \mathrm{L} / 24 \mathrm{~h}) \text {, } \\
\text { mean } \pm \mathrm{SD}\end{array}$ & $606.0 \pm 609.6$ \\
\hline
\end{tabular}

SD, standard deviation; BMI, body mass index; ASA, American Society of Anaesthesiologists physical status classification system; MEN 2A, multiple endocrine neoplasia type 2A; MEN $2 \mathrm{~B}$, multiple endocrine neoplasia type $2 \mathrm{~B}$; $\mathrm{VHL}$, von HippelLindau syndrome; NF1, neurofibromatosis type 1. tests with or without corrections were used for categorical variables. Furthermore, univariate, and multivariate logistic regression models were built. Baseline variables that had the $\mathrm{P}$ value $<0.1$ based on univariate analysis were included in a multivariate logistic regression model. Results were considered statistically significant when the $\mathrm{P}$ value was found to be less than 0.05. All data were analysed with Statsoft STATISTICA v.13.

\section{Ethical approval}

All procedures were performed in accordance with the ethical standards laid down in the 1964 Declaration of Helsinki and its later amendments. Informed consent for proposed surgical treatment was obtained from all patients before surgery. This study was approved by the institutional research ethics board (1072.6120.88.2018) and was registered on clinicaltrials.gov (NCT04566406).

\section{Results}

A total of 96 patients underwent unilateral laparoscopic adrenalectomy for pheochromocytoma. The mean age was $52.6 \pm 16.3$ years. The mean tumour size was $4.5 \pm 2.0 \mathrm{~cm} .86$ patients had a sporadic pheochromocytoma and 10 patients (10.4\%) had a familial disease. Demographic data and tumour characteristics are presented in Table 1.

Patients were divided into two groups: HI (+) group $(n=42)$ included patients who experienced HI during the operation and HI (-) group $(n=54)$ included patients who did not meet the criteria of HI.

Sixty-three patients were preoperatively treated with nonselective blockers and 33 patients with selective blockers. Mean operative time was $98.7 \pm 41.7 \mathrm{~min}$ and mean intraoperative blood loss was $165.7 \pm 381.2 \mathrm{~mL}$. In $26 \%$ of patients, postoperative complications occurred. There was one perioperative death - a patient with pheochromocytoma (ASA grade 4) died seven days after surgery due to cardiopulmonary failure. Three patients required intensive care unit stay due to severe hemodynamic instability. In summary, 18 patients after adrenalectomy required amines.

The median length of hospital stay was 3 days. There was no 30 days readmission after surgery. Treatment details and postoperative outcomes are presented in Table 2.

Univariate logistic regression models showed that the presence of diabetes mellitus and the size of adrenal tumour were related to the incidence of intraoperative 
Table 2 Treatment details and postoperative outcomes

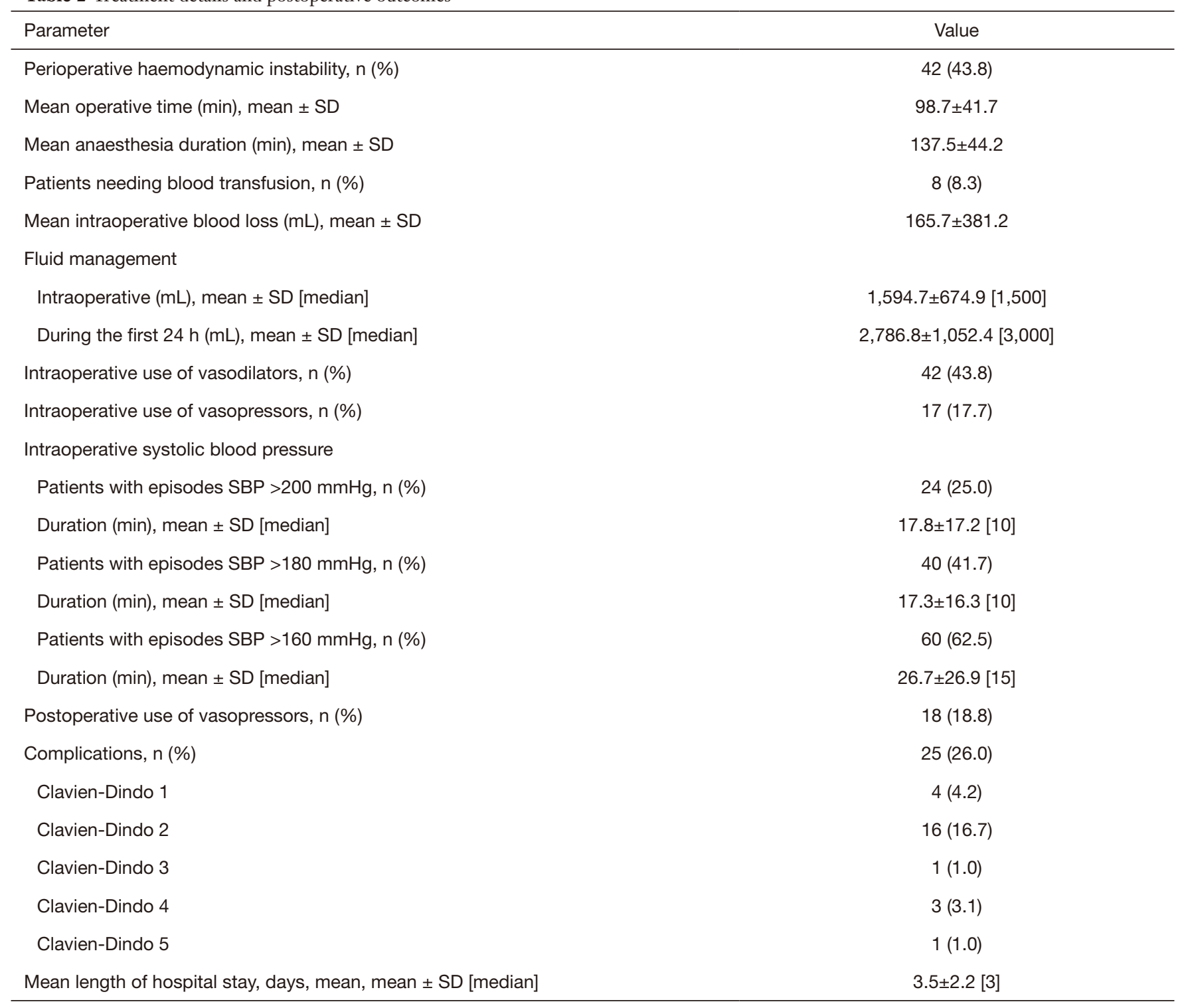

SD, standard deviation; SBP, systolic blood pressure.

hemodynamic instability (Table 3). In multivariate logistic regression model both the presence of diabetes (OR 2.79, 95\% CI: $1.1-7.1, \mathrm{P}=0.031)$ and size of the adrenal tumour (OR 1.43, 95\% CI: 1.09-1.86, P=0.009) remained significant risk factors for $\mathrm{HI}$.

In univariate analysis, hemodynamic instability (OR 4.07, 95\% CI: $1.54-10.79, \mathrm{P}=0.005$ ), operative time (OR $1.015,95 \%$ CI: $1.003-1.026, \mathrm{P}=0.01$ ), anaesthesia time (OR 1.016, 95\% CI: 1.005-1.027, $\mathrm{P}=0.004$ ), intraoperative administration of vasopressors (OR 6.0, 95\% CI: $1.96-$ $18.35, \mathrm{P}=0.002)$ and vasodilators (OR 4.93, $95 \% \mathrm{CI}$ :
1.81-13.44, $\mathrm{P}=0.002$ ) were associated with increased allcause morbidity. With regard to cardiovascular morbidity, we noticed that hemodynamic instability (OR 4.65, 95\% CI: 1.6-13.31, $\mathrm{P}=0.005$ ), diabetes (OR 2.83, 95\% CI: $1.05-7.63, \mathrm{P}=0.04$ ), operative time (OR 1.016, 95\% CI: 1.004-1.028, $\mathrm{P}=0.007$ ), anaesthesia time (OR 1.017, 95\% CI: $1.005-1.028, \mathrm{P}=0.004)$, intraoperative administration of vasopressors (OR 8.7, 95\% CI: 2.74-27.68, $\mathrm{P}=0.0002$ ) and vasodilators (OR 5.91, 95\% CI: 1.94-17.96, $\mathrm{P}=0.0017$ ) were significant factors. In multivariate analysis, necessity of intraoperative use of vasopressors remained independent 
Table 3 Logistic regression factors of perioperative HI

\begin{tabular}{|c|c|c|c|c|c|c|}
\hline Parameter & \multicolumn{3}{|c|}{ Univariate } & \multicolumn{3}{|c|}{ Multivariate } \\
\hline Sex (female vs. male) & 1.00 & $0.44-2.25$ & 0.9965 & & & \\
\hline Age (years) & 1.02 & $0.99-1.04$ & 0.1687 & & & \\
\hline BMI $\left(\mathrm{kg} / \mathrm{m}^{2}\right)$ & 1.00 & $0.93-1.08$ & 0.9678 & & & \\
\hline ASA (III-IV vs. I-II) & 1.19 & $0.53-2.69$ & 0.6747 & & & \\
\hline Diabetes (yes vs. no) & 3.65 & $1.52-8.76$ & 0.0037 & 2.79 & $1.10-7.10$ & 0.031 \\
\hline Cardiovascular disease (yes vs. no) & 1.31 & $0.52-3.27$ & 0.5695 & & & \\
\hline Renal diseases (yes vs. no) & 2.81 & $0.49-16.16$ & 0.2468 & & & \\
\hline Cerebrovascular diseases (yes vs. no) & 2.05 & $0.33-12.89$ & 0.4430 & & & \\
\hline Tumour site (right vs. left) & 0.74 & $0.32-1.68$ & 0.4667 & & & \\
\hline Size of the adrenal tumour & 1.48 & $1.14-1.92$ & 0.003 & 1.43 & $1.09-1.86$ & 0.009 \\
\hline PASS score & 1.05 & $0.85-1.30$ & 0.6510 & & & \\
\hline Genetic syndrome (yes vs. no) & 0.30 & $0.06-1.47$ & 0.1364 & & & \\
\hline Surgeon (others vs. the most experienced) & 1.82 & $0.80-4.14$ & 0.1536 & & & \\
\hline Blood transfusion & 3.79 & $0.72-20$ & 0.116 & & & \\
\hline Preoperative alpha-blockade (selective vs. nonselective) & 1.04 & $0.44-2.45$ & 0.9338 & & & \\
\hline
\end{tabular}

*, absolute values of methoxycatecholamines were not significant risk factors $\mathrm{HI}$ : urine metanephrine $(\mathrm{OR} 1.17,95 \% \mathrm{Cl}: 0.92-1.47$, $\mathrm{P}=0.197)$, urine normetanephrine (OR 1.09, 95\% Cl: 0.98-1.22, $\mathrm{P}=0.13)$ and urine methoxytyramine $(\mathrm{OR} 1.18,95 \% \mathrm{Cl}$ : 0.45-3.11, $\mathrm{P}=0.738$ ). HI, hemodynamic instability; OR, odds ratio; $\mathrm{Cl}$, confidence interval; BMI, body mass index; ASA, American Society of Anaesthesiologists physical status classification system; PASS, Pheochromocytoma of the Adrenal Gland Scaled Score; ULN, upper limit of normal.

risk factor for both all-cause (OR 6.32, 95\% CI: 1.44-27.75, $\mathrm{P}=0.015)$ and cardiovascular morbidity (OR 7.54, 95\% CI: $1.65-34.38, \mathrm{P}=0.009)$.

\section{Discussion}

Our study confirmed that the main factor affecting $\mathrm{HI}$ in patients undergoing laparoscopic pheochromocytoma resection is the size of the tumour. In addition, the presence of diabetes is also an independent factor of $\mathrm{HI}$ in our group of patients. However, the presence of HI was not a risk factor for morbidity in this group. The episodes of hypotension requiring intraoperative use of vasopressors were independent risk factor for both all-cause and cardiovascular morbidity.

Hemodynamic instability is one of the most frequent adverse events in patients undergoing laparoscopic pheochromocytoma removal. In our study the incidence of HI occurred in $44 \%$ of patients, mostly during surgery and this value is similar to the results of the previous studies 
$(11,19,20)$. Due to the frequent occurrence of persistent postoperative hypotensive episodes, often patients require a transfer to the intensive care unit. Fortunately, it is not reflected in the percentage of postoperative mortality ( $1 \%$ in our group). Recent findings suggest that the risk of postoperative hypotension may be reduced by limiting the use of preoperative beta-blockade therapy, which has been overused in earlier years (21).

The size of the adrenal tumour is the most commonly reported risk factor in the literature $(5,10,11)$. Larger tumours have been shown to significantly release catecholamines during pheochromocytoma removal and as a result to increase the number and duration of intraoperative hypertensive episodes $(10,22,23)$. In contrast to earlier findings, in our study degree of catecholamines production by the tumour at baseline was not a significant predictor of $\mathrm{HI}(6,11)$. It seems that the intraoperative manipulation on larger tumours leads to the release of greater amounts of catecholamines. Probably measuring catecholamines' release at the time of tumour removal could be a better predictor for HI than measurement of catecholamines' metabolites before the operation.

This is the first article that provides detailed insight into patients' comorbidities and therefore we were able to demonstrate that diabetes was also a risk factor for HI. It has been proven that diabetes mellitus affects functional as well as structural properties of the cardiovascular system (24). In particular, diabetic patients have higher arterial stiffness compared to non-diabetic ones, so these patients may be particularly susceptible to hypertension episodes (25).

However, numerous other risk factors for $\mathrm{HI}$ occur in the literature $(5,12,13)$. Possible reasons for this variability might be a lack of standardized perioperative both anaesthesiological and surgical management. In addition, discrepancies could arise from different HI definitions. In Kiernan et al. study, the use of selective blockade and open adrenalectomy were associated with episodes of HI, while Livingstone et al. showed a significant interaction between intraoperative magnesium use and preoperative SBP in predicting hemodynamic instability $(5,12)$.

Previous studies showed that $\mathrm{HI}$ during pheochromocytoma resection is associated with a higher risk of complications (11). Thus, we speculate that preventing perioperative HI will decrease morbidity rate after pheochromocytoma removal. Notably, $61.5 \%$ percent of patients in our study required intraoperative administration of vasopressors or vasodilators and almost every fifth patient had administered vasopressors postoperatively. Interestingly, in our study we did not demonstrate that $\mathrm{HI}$ is associated with a higher risk of complications. Our study showed that only intraoperative vasopressors use was an independent risk factor for postoperative all-cause and cardiovascular morbidity. In contrast to earlier findings, incidence of SBP $>160 \mathrm{mmHg}$ intraoperative episode, past medical history of coronary artery disease or female sex were not significant risk factors for postoperative morbidity $(3,6)$.

In the perioperative period, $8(8.3 \%)$ patients required blood transfusion. It is a large percentage compared to the data presented by Hauch et al. (26). He showed on a large cohort of patients that the percentage of bleeding related to adrenalectomy is $5.7 \%$. However, the group differed from the one presented by us. The author included all patients undergoing adrenalectomy in the analysis-we only analysed pheochromocytomas.

There has been debate over the years as to whether laparoscopy is safe access for this type of tumour. In our unit since 2012, laparoscopy is the method of choice during adrenalectomy. Patients with pheochromocytoma are no exception. Numerous recent studies have shown that laparoscopic access is equally safe and does not increase the risk of HI $(4,27)$. Furthermore, open surgery compared to laparoscopy leads to an increased number of episodes of SBP above $200 \mathrm{mmHg}$ (13). However, there are still questions in the literature whether the formation of pneumoperitoneum could lead to a massive release of catecholamines, which leads to hypertension and tachycardia (28). Nowadays laparoscopic access is the gold standard of surgical treatment for all adrenal tumours, including pheochromocytoma (15).

This study has limitations typical of a single centre study. Our material concerned a relatively limited number of patients, mainly due to the rare occurrence of this type of tumour. The most important limitation of the study seems to be the choice of the definition of hemodynamic instability. The multitude of definitions presented by various authors makes it difficult to compare the results. Bias may also be affected by the fact that included patients were operated over the span of 17 years. Over the years, both operators and anaesthesiologists experience have changed. Nevertheless, the frequency of $\mathrm{HI}$ in smaller time intervals of several years was comparable. The use of alpha-blocker preparation, modification of intra- and postoperative care, changes in the treatment of hypertension, and increased proficiency in laparoscopic surgery over the years make the 
comparison even more difficult.

\section{Conclusions}

Hemodynamic instability occurred in almost half of the patients operated on due to pheochromocytoma. In our group, the size of the adrenal tumour and the presence of diabetes were independent factors of HI during pheochromocytoma resection. Additionally, intraoperative use of vasopressors was an independent predictor for both postoperative all-cause and cardiovascular morbidity.

\section{Acknowledgments}

Funding: None.

\section{Footnote}

Reporting Checklist: The authors have completed the STROBE reporting checklist. Available at http://dx.doi. org/10.21037/gs-20-783

Data Sharing Statement: Available at http://dx.doi. org/10.21037/gs-20-783

Peer Review File: Available at http://dx.doi.org/10.21037/gs20-783

Conflicts of Interest: All authors have completed the ICMJE uniform disclosure form (available at http://dx.doi. org/10.21037/gs-20-783). The authors have no conflicts of interest to declare.

Ethical Statement: The authors are accountable for all aspects of the work in ensuring that questions related to the accuracy or integrity of any part of the work are appropriately investigated and resolved. All procedures were performed in accordance with the ethical standards laid down in the 1964 Declaration of Helsinki and its later amendments. Informed consent for proposed surgical treatment was obtained from all patients before surgery. This study was approved by the institutional research ethics board (1072.6120.88.2018) and was registered in the clinicaltrials.gov (NCT04566406).

Open Access Statement: This is an Open Access article distributed in accordance with the Creative Commons Attribution-NonCommercial-NoDerivs 4.0 International
License (CC BY-NC-ND 4.0), which permits the noncommercial replication and distribution of the article with the strict proviso that no changes or edits are made and the original work is properly cited (including links to both the formal publication through the relevant DOI and the license). See: https://creativecommons.org/licenses/by-nc-nd/4.0/.

\section{References}

1. Lenders JWM, Eisenhofer G, Mannelli M, et al. Phaeochromocytoma. Lancet 2005;366:665-75.

2. Lenders JWM, Duh QY, Eisenhofer G, et al. Pheochromocytoma and paraganglioma: An endocrine society clinical practice guideline. J Clin Endocrinol Metab 2014;99:1915-42.

3. Brunaud L, Nguyen-Thi PL, Mirallie E, et al. Predictive factors for postoperative morbidity after laparoscopic adrenalectomy for pheochromocytoma: a multicenter retrospective analysis in 225 patients. Surg Endosc 2016;30:1051-9.

4. Bai S, Yao Z, Zhu X, et al. Risk factors for postoperative cardiovascular morbidity after pheochromocytoma surgery: a large single center retrospective analysis. Endocr J 2019;66:165-73.

5. Kiernan CM, Du L, Chen X, et al. Predictors of hemodynamic instability during surgery for pheochromocytoma. Ann Surg Oncol 2014;21:3865-71.

6. Gaujoux S, Bonnet S, Lentschener C, et al. Preoperative risk factors of hemodynamic instability during laparoscopic adrenalectomy for pheochromocytoma. Surg Endosc 2016;30:2984-93.

7. Schweitzer ML, Nguyen-Thi PL, Mirallie E, et al. Conversion During Laparoscopic Adrenalectomy for Pheochromocytoma: A Cohort Study in 244 Patients. J Surg Res 2019;243:309-15.

8. Thompson JP, Bennett D, Hodson J, et al. Incidence, risk factors and clinical significance of postoperative haemodynamic instability after adrenalectomy for phaeochromocytoma. Gland Surg 2019;8:729-39.

9. von Elm E, Altman DG, Egger M, et al. The Strengthening the Reporting of Observational Studies in Epidemiology (STROBE) statement: guidelines for reporting observational studies. Ann Intern Med 2007;147:573-7.

10. Bruynzeel H, Feelders RA, Groenland THN, et al. Risk factors for hemodynamic instability during surgery for pheochromocytoma. J Clin Endocrinol Metab 2010;95:678-85. 
11. Aksakal N, Agcaoglu O, Sahbaz NA, et al. Predictive factors of operative hemodynamic instability for pheochromocytoma. Am Surg 2018;84:920-3.

12. Livingstone $M$, Duttchen $K$, Thompson J, et al. Hemodynamic Stability During Pheochromocytoma Resection: Lessons Learned Over the Last Two Decades. Ann Surg Oncol 2015;22:4175-80.

13. Vorselaars WMCM, Postma EL, Mirallie E, et al. Hemodynamic instability during surgery for pheochromocytoma: comparing the transperitoneal and retroperitoneal approach in a multicenter analysis of 341 patients. Surgery 2018;163:176-82.

14. Pisarska M, Pedziwiatr M, Budzyński A. Perioperative hemodynamic instability in patients undergoing laparoscopic adrenalectomy for pheochromocytoma. Gland Surg 2016;5:506-11.

15. Gagner M, Lacroix A, Bolté E. Laparoscopic Adrenalectomy in Cushing's Syndrome and Pheochromocytoma. N Engl J Med 1992;327:1033.

16. Major P, Matłok M, P dziwiatr M, et al. Do we really need routine drainage after laparoscopic adrenalectomy and splenectomy? Wideochir Inne Tech Maloinwazyjne 2012;7:33-9.

17. Stefanidis D, Goldfarb M, Kercher KW, et al. SAGES guidelines for minimally invasive treatment of adrenal pathology. Surg Endosc 2013;27:3960-80.

18. Ramakrishna H. Pheochromocytoma resection: Current concepts in anesthetic management. J Anaesthesiol Clin Pharmacol 2015;31:317-23.

19. Kercher KW, Park A, Matthews BD, et al. Laparoscopic adrenalectomy for pheochromocytoma. Surg Endosc

Cite this article as: Pisarska-Adamczyk M, Zawadzka K, Więckowski K, Przęczek K, Major P, Wysocki M, Małczak P, Pędziwiatr M. Risk factors for hemodynamic instability during laparoscopic pheochromocytoma resection: a retrospective cohort study. Gland Surg 2021;10(3):892-900. doi: 10.21037/gs20-783
2002;16:100-2.

20. Kasahara T, Nishiyama T, Takahashi K. Laparoscopic adrenalectomy for pheochromocytoma: Evaluation of experience and strategy at a single institute. BJU Int 2009;103:218-22.

21. Lim ES, Akker SA. Haemodynamic instability of the phaeochromocytoma. Gland Surg 2020;9:869-71.

22. Kinney MAO, Warner ME, Van Heerden JA, et al. Perianesthetic risks and outcomes of pheochromocytoma and paraganglioma resection. Anesth Analg 2000;91:1118-23.

23. Scholten A, Vriens MR, Cromheecke GJE, et al. Hemodynamic instability during resection of pheochromocytoma in MEN versus non-MEN patients. Eur J Endocrinol 2011;165:91-6.

24. Agnoletti D, Lieber A, Zhang Y, et al. Central hemodynamic modifications in diabetes mellitus. Atherosclerosis 2013;230:315-21.

25. Aoun S, Blacher J, Safar ME, et al. Diabetes mellitus and renal failure: Effects on large artery stiffness. J Hum Hypertens 2001;15:693-700.

26. Hauch A, Al-Qurayshi Z, Kandil E. Factors associated with higher risk of complications after adrenal surgery. Ann Surg Oncol 2015;22:103-10.

27. Li J, Wang Y, Chang X, et al. Laparoscopic adrenalectomy (LA) vs open adrenalectomy (OA) for pheochromocytoma (PHEO): A systematic review and meta-analysis. Eur J Surg Oncol 2020;46:991-8.

28. Naranjo J, Dodd S, Martin YN. Perioperative Management of Pheochromocytoma. J Cardiothorac Vasc Anesth 2017;31:1427-39. 